\title{
The use of proteomics in biomarker discovery in neurodegenerative diseases
}

\author{
Pia Davidsson ${ }^{\mathrm{a}, *}$ and Magnus Sjögren ${ }^{\mathrm{a}, \mathrm{b}}$ \\ ${ }^{a}$ Discovery Medicine, AstraZeneca R\&D, Mölndal, Sweden \\ ${ }^{\mathrm{b}}$ Department of Neuropsychiatry, Sahlgren's University Hospital, Mölndal, Sweden
}

\begin{abstract}
Biomarkers for neurodegenerative diseases should reflect the central pathogenic processes of the diseases. The field of clinical proteomics is especially well suited for discovery of biomarkers in cerebrospinal fluid (CSF), which reflects the proteins in the brain under healthy conditions as well as in several neurodegenerative diseases. Known proteins involved in the pathology of neurodegenerative diseases are, respectively, normal tau protein, $\beta$-amyloid (1-42), synaptic proteins, amyloid precursor protein (APP), apolipoprotein E (apoE), which previously have been studied by protein immunoassays. The objective of this paper was to summarize results from proteomic studies of differential protein patterns in neurodegenerative diseases with focus on Alzheimer's disease (AD). Today, discrimination of AD from controls and from other neurological diseases has been improved by simultaneous analysis of both $\beta$-amyloid (1-42), total-tau, and phosphorylated tau, where a combination of low levels of CSF- $\beta$-amyloid 1-42 and high levels of CSF-tau and CSF-phospho-tau is associated with an AD diagnosis. Detection of new biomarkers will further strengthen diagnosis and provide useful information in drug trials. The combination of immunoassays and proteomic methods show that the CSF proteins express differential protein patterns in AD, FTD, and PD patients, which reflect divergent underlying pathophysiological mechanisms and neuropathological changes in these diseases.
\end{abstract}

Keywords: Alzheimer, biomarkers, cerebrospinal fluid, diagnosis, frontotemporal dementia neurodegenerative diseases, Parkinson's disease, proteomics

\section{Introduction}

In recent years, there has been a growing interest in applying proteomics to research on clinical diagnostics and predictive medicine of neurodegenerative disorders. The goal of this research has been to identify disease markers, i.e. diagnostic biomarkers, with or without association to known pathophysiological mechanisms and that can be used to improve the accuracy of the clinical diagnosis. The process of biomarker discovery involves analysis of biomarkers in clinical human samples or samples from animal models for example peptide and proteins profiling, lipid analysis, metabonomics or morphological studies. Since pro-

*Corresponding author: Pia Davidsson, Discovery Medicine/ Molecular Sciences, AstraZeneca R\&D, Mölndal, SE-431 83 Mölndal, Sweden. Tel.: +46 3170641 46; E-mail: pia.davidsson@ astrazeneca.com. teins are responsible for almost all biological processes in an organism, changes in the concentration and/or to their structures are likely to reflect the effects of a disease, thereby making proteins attractive candidates in biomarker discovery.

By using proteomics in biomarker discovery, the type and concentration of a protein (or a group of proteins) can be followed at any given time in a proteome and the correlation of those patterns present in a "disease state" as compared to "healthy state" can be of high diagnostic value as well as of value to understanding the underlying mechanisms of the disease. These disease-specific proteins can assist medicine by enabling earlier detection and treatment of a disease. Because disease often will involve a changed expression of a protein pattern, a combination of several biomarkers is generally more effective than a single one.

The clinical picture commonly determines the diagnosis and progression of neurodegenerative diseases, 
however the neuropathological investigation gives the definite diagnosis. Sometimes, the clinical picture is vague or complex and clinical diagnostic decisions are difficult to make. To facilitate an early diagnosis, additional diagnostic tools would be of great interest. The field of clinical proteomics is especially well suited for discovery of biomarkers in cerebrospinal fluid (CSF), which reflects the proteins in the brain under healthy conditions as well as in several neurodegenerative diseases.

There are two strategies for the search of protein biomarkers in body compartments: One is the direct search in peripheral fluids where the biomarker concentration is expected to be relatively low and today's detection methods will not allow their identification. The other approach is the search for new biomarkers in diseased tissue where the biomarker protein is present at a higher concentration facilitating the protein identification by mass spectrometry (MS). An inherent risk in the tissue approach is the fact that the candidate marker identified in tissue cannot be detected in CSF or serum.

Post-mortem brain tissue has the advantage of allowing direct analysis of proteins from specific regions. It is, however, questionable whether pathophysiological mechanisms can be elucidated from autopsy material, because it is not possible to define what started the process. Biopsies, on the contrary, taken during surgery may reflect chemistry of a living brain, however, ethic considerations make it a difficult issue.

Body fluids, such as CSF, serum, or urine, represents a cellular, protein-rich information reservoir that contains traces of what has been encountered during its circulation throughout the body. Being easily accessible, and present in sufficient amounts for protein profiling, body fluids offer an attractive medium to biomarker analysis. Analysis of CSF is so far the most convenient method for studying the biology of neurodegenerative diseases in living patients, and has been used as a major diagnostic tool for a wide range of conditions affecting both the central and the perifer nervous system.

Biomarkers for neurodegenerative diseases should reflect the central pathogenic processes of the diseases for example the neuronal degeneration, the disturbance in the beta-amyloid $(\mathrm{A} \beta)$ metabolism or the synaptic loss in AD pathology. Known proteins involved in the pathology of neurodegenerative diseases are, respectively, normal tau protein, A $\beta-42$, synaptic proteins, amyloid precursor protein (APP), apolipoprotein $\mathrm{E}$ (apoE), which previously have been studied by immunoassays by us and several other groups.

The objective of this paper was to summarize results from proteomic studies of differential protein patterns in neurodegenerative diseases with focus on Alzheimer's disease (AD).

\section{Proteomics methods for the identification of diagnostic markers}

Proteomic research combines high-resolution separation techniques applied to complex protein mixtures with state-of-the-art identification methods such as mass spectrometry (MS) or immunoassays. It is generally agreed that none of the existing separation and identification methodologies on its own can give a full account of the protein composition or the protein expression in complex mixtures e.g. biological fluids such as CSF, serum, urine, or tissue extracts. This limitation, however, has not prevented the use of existing methods or the combination of existing technologies to provide valuable information on a wide range of proteins, especially when either their absence or presence or their level of expression can be correlated to a disease state.

For a global proteomic study, two-dimensional gel electrophoresis (2-DE), a combination of prefractionation and 2-DE, or multi-parametric immunoassays will be used to study expression and post translational modification of proteins, while preparative 2-DE or 2-D liquid chromatography (LC) coupled to tandem MS will be used for identification and discovery of new protein biomarkers. The use of a combined strategy for peptide/ protein profiling of CSF is expected to offer new perspectives for the discovery of new biomarkers.

\subsection{Two-dimensional gel electrophoresis}

After nearly thirty years, 2-DE is still the method of choice for separating, comparing and detecting quantitative changes in biomarker expression patterns [41,58, 76,96]. Proteins are separated according to their charge and their molecular weight, allowing resolution of multiple isoforms and variants of the same proteins. When coupled to MS, individual polypeptide components can be identified. However, there is still a resistance to the widespread use of 2-D gels. One reason is the hard work involved in the separation technology. Another limitation are the in-build limitations of the technology that several classes of proteins are difficult to resolve including acidic/alkaline proteins, and hydrophobic proteins. Quantitative measurements are limited to a narrow dynamic range, and as a result, the major abundant proteins mask lower abundance proteins. In spite of that, 2-D gels have been used successfully for differential protein display in biomarker discovery of neurodegenerative diseases. 


\subsection{Surface-enhanced laser desorption/ionization mass spectrometry}

Surface-enhanced laser desorption/ionization (SELDI) MS is another proteomic approach for biomarker discovery $[16,74,75]$. It combines two powerful techniques; chromatography and MS. Proteins are captured either by adsorption, partition, electrostatic interaction, or affinity chromatography on a solid-phase protein-chip surface. The retained proteins are subsequently ionised and detected by time-of-flight (TOF) MS. SELDI can provide a rapid protein expression profile from a variety of biological samples. This system is most effective for profiling low molecular weight proteins up to $20 \mathrm{kDa}$, providing a complementary visualization technique to 2-DE.

\subsection{Prefractionation strategies}

A few abundant proteins, i.e. albumin and immunoglobulins, limit the total amount of CSF or serum proteins that can be loaded on the 1-D gels, 2-D gels or by SELDI analysis, resulting in difficulties to detect low abundant proteins. By using liquid phase isoelectric focusing (LP-IEF), first proposed by Bier [5] as a prefractionation step prior to 2-DE, we have previously shown that less abundant CSF proteins can be enriched, thus more easily detected and identified by MS [24]. Protein enrichment by LP-IEF has the advantage of being a non-denaturating technique i.e. the peptides/proteins usually retain their biological activity during the procedure. The Rotofor cell has been developed for preparative scale, free solution IEF applications. Since the separation is performed in liquid phase, no gel elution or other steps are required. LP-IEF has been used in the first dimension and in combination either with continuous elution SDS-PAGE [22,70], immunoblotting [21], or 1-D gels and electro elution in the second dimension of the protein separation [23]. An important advantage of using LP-IEF as a prefractionation step for enrichment of CSF proteins is the high load capability of the Rotofor cell, thereby making it possible to enrich low abundant proteins in sufficient amounts for detection/quantification by MS. During several years alternative prefractionation methods prior to 2-DE has been reported, each with its advantages and disadvantages.

A variety of depletion methods for specific removal of high abundant proteins from body fluids have also been developed. Several major strategies are available concerning the mechanisms of removal of human serum albumun (HSA) and IgG. In the case of HSA, binding can be achieved by either dye-ligands such as the widely recognized Cibacron Blue F3GA and derivatives thereof [35] or specific antibodies [93,101]. The removal of IgG is commonly achieved by immobilizing protein $A$ or protein $\mathrm{G}$ onto the affinity resins, which binds to the Fc region of the $\operatorname{IgG}[1,6,14]$, but specific antibodies can also be used. Only a few comparative studies of albumin and $\mathrm{IgG}$ depletion methods have previously been performed [37,93]. However, additional depletion methodologies have recently become available therefore five commercially available depletion columns have been comprehensively evaluated and compared regarding their efficiency, specificity and reproducibility for removal of high abundant proteins in biological fluids [7]. Our results showed that all five depletion columns tested removed albumin and IgG with high efficiency. We found that based on reproducibility and binding specificity, the Multiple Affinity Removal Column that removed a total of six high abundant proteins (albumin, IgG, antitrypsin, IgA, transferrin and haptoglobin) offered the most promising depletion approach. Depleted serum from the Multiple Affinity Removal column was further evaluated by 2DE analysis, and the results indicated increased resolution and improved intensity of low abundant proteins in a reproducible fashion [7].

\subsection{2-D LC-MS/MS and preparative 2-DE}

An alternative proteomic approach for resolving complex protein mixtures is 2-D LC coupled to MS/MS [37,56,65]. The separation is performed in a liquid chromatographic system consisting of two columns with different separation mechanisms. 2-D LC is time-consuming and this technique is not yet suitable for clinical testing.

A strategy employing LP-IEF in the first dimension, 1-D gels in combination with gel elution in the second dimension and MS/MS analysis has been used for discovery and identification of proteins from human CSF and brain tissue [23]. Advantages of this method compared to 2-D LC are the speed of analysis and also the easy handling.

\section{Tau protein}

Tau protein is a microtubule-associated protein found in high concentration in the axon of neurons and glial cells of the CNS. Tau proteins exist as many heterogeneous isoforms derived from both differential splic- 
ing of tau-mRNA and post-translation modification of the protein. Characterization of tau protein from CSF by the combination of LP-IEF and immunoblotting showed that both phosphorylated and unphosphorylated tau isoforms are present in CSF, and the tau protein appeared both in truncated and as full length forms in CSF [91].

Using monoclonal antibodies that detect all isoforms of tau independent of phosphorylation, ELISA methods have been developed that measure "total" CSF tau level $[10,99,104]$. An increase in CSF tau in AD patients has been found in a numerous of studies. The sensitivity to identify AD patients varies between reports, but has been around $80-90 \%$ [2,3,54], while its specificity in differenting AD from normal aging has been in the range of $85-90 \%$. However, other studies have found that high tau levels also are found in other neurodegenerative diseases as for example in frontal lobe dementia (FTD) [39], vascular dementia [10], and Parkinson's disease (PD) [69].

The level of CSF tau reflects the degree of neuronal degeneration and damage [10]. This suggestion is supported by the findings that a marked transient increase in CSF-tau is found after acute stroke, with a positive correlation between CSF-tau and infarct size as measured by CT [49,51].

To further elucidate the involvement of total tau and phosphorylated tau in various dementia disorders, the CSF concentration of tau and phospho-tau in probable and possible AD, FTD, and, PD have been determined [91]. The results suggests that the CSF concentrations of tau and phosphotau are increased in about two thirds of probable $\mathrm{AD}$, and in half of those with possible AD, but are normal in FTD, PD, and controls. This probably reflects that different pathophysiological mechanisms are active in various neurodegenerative diseases.

\section{Amyloid precursor protein}

The amyloid precursor protein (APP) is a ubiquitously expressed transmembrane glycoprotein. Different ways of processing APP can occur involving at least three types of proteolytic enzymes: $\alpha, \beta$, or $\gamma$ secretase. The soluble forms of APP ( $\alpha$-sAPP and APP $\beta$ sAPP) are present in brain and CSF $[73,88]$. Studies on CSF from sporadic forms of AD patients compared to healthy controls have not discriminated between these two forms using sandwich enzyme linked immunosorbent assay methods [71]. Results from other studies on the total level of sAPP in AD compared to controls are contradictory, ranging from no significant difference [53], to lower levels [72,80,101].

\section{Beta amyloid peptides}

Under normal conditions the soluble $\mathrm{A} \beta$ peptides are present in the brain and CSF [87]. Characterization of soluble $\mathrm{A} \beta$ from $\mathrm{CSF}$ have revealed heterogeneity with respect to the length of both the $\mathrm{N}$-terminal and C-terminal of $\mathrm{A} \beta$ [103]. The multiple forms of $\mathrm{A} \beta$ peptides are also seen in the amyloid deposits [64]. Recently, Wiltfang and colleagues found that another form of $\mathrm{A} \beta, \mathrm{A} \beta 1-38$ is present in higher concentration than $\mathrm{A} \beta 1-42$ in CSF, and is thus the second most prominent $\mathrm{A} \beta$ peptide specie in CSF [105].

Most studies have been focused on quantification of the two $\mathrm{A} \beta$ peptides, $\mathrm{A} \beta 1-40$ and $\mathrm{A} \beta 1-42$ in CSF. Using different assays specific for $\mathrm{A} \beta 1-42$, a marked increase in $\mathrm{A} \beta 1-42$ in $\mathrm{CSF}-\mathrm{AD}$ has been found in a numerous of studies. However, one study found an increase in $\mathrm{A} \beta 1-42$ in $\mathrm{AD}$ [57], which may be due to methodological differences or differences in patient and control groups. The sensitivity to identify AD patients has been approximately $80-90 \%$, while its specificity in differencing $\mathrm{AD}$ from normal aging has been in the range of 85-90\% [34,54]. In contrast, the level of CSF- $\mathrm{A} \beta 1-40$ is unchanged in $\mathrm{AD}$ patients compared to healthy controls [55].

Lower levels of $\mathrm{A} \beta 42$ has also been found in FTD and VAD patients $[54,77,91]$. The reduction of CSF$\mathrm{A} \beta 1-42$ is reflecting the deposition of the $\mathrm{A} \beta$ peptide in senile plaques, with lower levels secreted to the CSF.

An $\mathrm{A} \beta$ SELDI immunoassay was first developed to analyze different $\mathrm{A} \beta$ peptides found in cell culture medium. The pattern of $\mathrm{A} \beta$-peptides found in human CSF and in brain homogenate from AD patients have been investigated using the same method $[15,61]$. These data suggest the presence of a novel $\mathrm{A} \beta$ peptide, elongated at the $\mathrm{C}$-terminus, corresponding to $\mathrm{A} \beta 1-45$ or $\mathrm{A} \beta 1-46$ according to its molecular mass in CSF. This peptide was only observed in CSF of AD patients. Moreover the signal corresponding to $\mathrm{A} \beta 1-42$ was decreased in the CSF of AD patients when compared with non-demented controls, and consistent with the results by ELISA quantitation. 


\section{Apolipoprotein E}

ApoE is an apolipoprotein with a molecular weight of approximately $34 \mathrm{kDa}$. The apoE gene is located on chromosome 19 , and the protein consists of three isoforms occurring in varying frequency among the general population: apoE2 (7-8\%), E3 (77-78\%) and E4 $(14-16 \%)$ [31,84]. ApoE is normally circulating in plasma and is a constituent of plasma lipoprotein particles mediating uptake of those into the cells $[63,79,83]$. In humans the brain is the second most important site for biosynthesis of apoE [30]. In AD, microglial cells surrounding the core of senile plaques (SPs), extracellular deposits of aggregated $\beta$-amyloid, are positive for apoE protein [98]. The results on apoE levels in AD brain tissue are contradictory though, with apoE levels reported unchanged or decreased in different $\mathrm{AD}$-brain regions $[4,43,48,78]$ as compared to controls. The variations are probably due to differences in methodology and patient materials.

Differences in the apoE isoforms have also been shown. The apoE4 isoform is associated as a susceptibility gene for AD [18,85,94]. Studies on CSF-apoE in $\mathrm{AD}$ patients have also given inconclusive results $[9$, $59,60]$, which might be related to confounding factors interfering with sample handling and/or analyses. In the study by Hesse et al. [50], reduced levels of apoE in CSF of AD patients were found. Both in the AD group and in the control a group, higher level of CSFapoE was found in individuals possessing the apoE4 alleles. These results show that CSF-apoE is reduced in $\mathrm{AD}$, and that the handling of CSF is a critical factor, which might explain the discrepant results from previous studies.

The known change of Cys to Arg in position 112 of the apoE4 isoform has been identified by the combination of LP-IEF in combination with SDS-PAGE, electro elution and MALDI TOF MS analysis [52]. This change was detected in CSF of AD patients, reflecting the increased frequency of the apoE4 allele in this population. This peptide was not detected in CSF samples from healthy control individuals.

\section{Synaptic proteins}

Neuropathological studies strongly support that a synapse loss is an essential feature associated with neurodegenerative disorders. This was first demonstrated by ultra structural studies $[27,28]$ with immunohistochemistry using the synaptic vesicle proteins synapsin
I [39] and synaptophysin [97] as markers. A correlation was found between synaptic loss and severity of dementia, which suggest a close relationship between synaptic pathology and the cognitive decline in $\mathrm{AD}[20$, 95]. The synaptic vesicle proteins rab3a, synaptotagmin, and synaptophysin, the presynaptic protein GAP43 and the post-synaptic protein neurogranin have all been found to be reduced in the frontal, temporal, and parietal cortex and hippocampus in AD compared to controls [20]. Reduced levels of synaptic vesicle proteins have also been found in several other studies [13, 38].

Synaptic proteins in CSF might be useful as markers of the synaptic degeneration. However, most synaptic proteins are membrane proteins with low water solubility and are present in very low concentration in CSF. Attempts to define synaptic pathology in CSF came first from other markers of synapses such as chromogranin A and ganglioside GM1, which were shown to be reduced in AD patients compared to controls $[8,10]$. Previously, one synaptic vesicle protein, synaptotagmin, was for the first time detected in CSF using a procedure including affinity chromatography followed by microreversed phase chromatography, and enhanced chemiluminescence's immunoblotting [19]. A reduction of synaptotagmin was first found in both brain tissue and also in lumbar CSF of in AD patients [19,20], implying that CSF reflects the composition of synaptic proteins in the brain under normal and pathological conditions. Other synaptic proteins were not detectable using this procedure. The synaptic proteins can neither be detected by ordinary sodium dodecyl sulphate polyacrylamide gel electrophoresis (SDS-PAGE) and Westernblotting, even after CSF concentration. LP-IEF in combination with immunoblotting has been used for enrichment and detection of neuron-specific proteins that are involved in neurodegenerative disorders [21,91]. Six synaptic proteins including rab3a, synaptotagmin, GAP-43, SNAP-25, synapsin, and neurogranin were detected in nanogram per litre quantities in human CSF using this method. These results showed that several of the synaptic proteins could be identified in CSF in trace amounts, showing that these proteins can be quantitative, which may reflect altered synaptic function and integrity as it is known to occur in neurodegenerative diseases.

Therefore, a sandwich-ELISA was developed for determination of one synaptic vesicle protein, phosphosynapsin-1, in individual CSF samples [82]. The sandwich-ELISA was based on a rabbit anti-phosphosynapsin antibody and a synapsin 1 specific mono- 
clonal antibody. Using this assay, phospho-synapsin-1 was determined in CSF of 20 AD patients and 14 controls. The level of phospho-synapsin-1 was increased in $\mathrm{AD}$ group $(0.164+0.15 \mathrm{AU}$, mean $+\mathrm{SD})$ compared to controls $(0.033+0.05 \mathrm{AU}$, mean $+\mathrm{SD})$. Phospho synapsin levels in almost all controls were so low that the proteins could not be detected with our ELISA method. Earlier attempts to measure synapsin in individual CSF samples also showed undetectable levels in healthy individuals [86]. In brain tissue, either reduced or unchanged levels of synapsin have previously been demonstrated in AD. In vitro studies showed reduced phosphorylation of synapsin 1 in AD post mortem tissue suggesting that perturbation of synapsin phosphorylation occur early in pathological states such as AD.

CSF-GAP-43 has also been analysed in neurodegenerative diseases including AD, FTD, and PD patients compared to controls. CSF-GAP-43 was only significantly reduced in PD compared to the other groups [90, 92], and was not changed in AD, or FTD compared to controls. This could imply that degeneration of presynaptic terminals was limited in all groups. However based on previous findings using immunoblotting/immunohistochemistry methods this seems unlikely $[12,28]$. An other explanation is that the results reflect the concomitant degeneration and regeneration of synapses, the sum of which causes only mild changes in the CSF-GAP-43 levels. Our previous study on brain tissue levels GAP-43 found both decreases and increases in different regions in $\mathrm{AD}$ [13], which supports this notion.

All these results show that characterization of proteins and their modification (amino acid substitutions, glycosylation, or phosphorylation) in CSF is an important tool in the investigation of the pathophysiology of neurodegenerative diseases.

\section{CSF protein profiling studies in neurodegenerative diseases}

\subsection{Direct 2-DE}

In order to expand the search for diagnostic biomarkers, which would lead to a better understanding of the pathophysiological mechanisms of neurodegeneration, 2-DE investigations of the CSF have been performed $[25,26,36,44-47,68,89,106]$. Using 2-DE analysis and the silver staining technique, large differences in protein patterns in CSF between patients with brain disorders such as AD, schizophrenia, PD and multi- ple sclerosis were shown [44-47,68], however many of these proteins have not yet been identified.

In the proteomic study of CSF proteins in a group of $15 \mathrm{AD}$ patients, the levels of six proteins and their isoforms, including proapolipoprotein, apolipoprotein $\mathrm{E}, \beta-2$ microglobulin $(\beta-2 \mathrm{~m})$, retinol binding protein (RBP), transthyretin (TTR), and ubiquitin were significantly altered. The most notable changes were seen among the apolipoproteins, especially proapolipoprotein [24]. Furthermore, the partial CSF proteome of 7 $\mathrm{AD}$ patients and 7 controls were compared using microstrips ( $\mathrm{pH}$ 4.7-5-9) [81]. Comparing the intensity of spots between AD and controls, 18 spots were found to be significantly up- or down regulated $(p<0.05)$. Eight proteins were significantly reduced in CSF of AD patients and they were identified as kininogen, one isoform of $\alpha-1 \beta$ glycoprotein, and two isoforms of apoJ, three isoforms of apoE, two isoforms of apoA1, $\alpha$-trace, cell cycle progression 8 proteins and RBP. Only one protein, one isoform of $\alpha$-1-antitrypsin, was increased in $\mathrm{AD}$ patients compared to controls. Previously detected protein changes were confirmed including apoE, and apoA1. Some new proteins changes were identified like kininogen, $\alpha-1 \beta$ glycoprotein, apoJ, $\beta$-trace, cell cycle progression 8 and $\alpha$-1-antitrypsin. In contrast, Fonteh and Harrington reported at the 2002 meeting in Siena [33] an increase of specific isoforms of apolipoproteins A1, J, K and Prostaglandin D synthase (PGDS) in the CSF of AD study participants.

The most affected proteins in AD were among the apolipoproteins, especially proapolipoprotein. As constituents of high-density lipoprotein (HDL), apoE and apoA1 have important roles in controlling the lipid homeostasis in peripheral cells. The biological function of apolipoproteins is less clear, but an involvement of them in transporting cholesterol out and in from neurons are obvious. Interestingly, there is also a growing evidence of a link between a disturbance in the apolipoproteins and cholesterol metabolism in AD [29]. Determination of CSF-apoE has earlier showed reduced levels in $\mathrm{AD}$ patients compared to controls [66], which is consistent with our results. In contrast to our study, no significant difference in apoA 1 brain expression or in CSF levels have been found between AD patients and controls [67]. The conflicting data between our study and other studies might be due to the more sensitive detection of different isoforms of apoA1 by 2-DE. An immunological determination of total apoA1 gives only the information of the total apoA 1 immunoreactivity and not specific differences between apoA1 isoforms. ApoJ, also called clusterin, has been shown to 
be present in the senile plaques and increased levels have been reported in AD brain [62].

Several new proteins changes were demonstrated in CSF using the micro-narrow range IPG strips. Kininogen involved in the kallikrein/kinin system, has earlier been linked to AD. Increased cleavage of kininogen was found in CSF of AD patients and is thought to interact with (A in AD. Only one protein was significantly increased in CSF of AD patients, i.e. $\alpha$-1-antitrypsin, a serine protease that has previously been localised in neurofibrillary tangles and senile plaques.

Several of the altered proteins in the comparison between AD patients and controls are isoforms of glycoproteins such as $\alpha$-1-antitrypsin, $\beta$-trace, $\alpha-1 \beta$ glycoprotein, apoJ, and apoE. Therefore, potential changes in the glycosylation patterns of these proteins and their role in $\mathrm{AD}$ are important in the etiology of $\mathrm{AD}$. Fourier transform ion cyclotron resonance (FT-ICR) MS and infrared multiphoton dissociation (IRMPD) have recently been used to structurally determine the glycosylation states of altered isoforms of CSF proteins, separated by 2-DE [42], and might be an important tool for investigation of post translational modifications.

In an other proteomic study, the CSF proteins were analysed in a group of FTD patients, which is the second most common type of dementia. The levels of six proteins and their isoforms were altered in FTD patients compared to controls including granine-like neuroendocrine precursor, pigment epithelium derived factor, RBP, apoE, and haptoglobin [26]. We showed for the first time that several proteins involved in FTD pathology were not altered in the CSF of AD patients, and vice versa, thus establishing differences in pathophysiological mechanisms between FTD and AD, two of the most common neurodegenerative disorders [25,26].

Recently, the combination of 2-DE and PCA has been used for studying biomarkers in AD-CSF compared to controls [17]. They detected a panel of nine biomarkers, which was used to distinguish normals from AD-CSF. Thus far they have not identified any of the proteins. We have also examined the ability of the 2-DE technology to classify CSF samples into appropriate categories using multivariate statistical methods. This recent study demonstrated the potential utility of the proteomic approach to classify AD CSF as a distinct group from normal CSF and other types of dementias, using a panel of protein markers (96 proteins), defined by the use of multivariate statistical methods [36]. The combination of 2-DE and PCA measures the expression of a large number of CSF proteins, which could permit the development of a multiple marker test.

\subsection{LP-IEF in combination with 2-DE}

In order to even more widen our proteomic search for protein differences in the CSF of AD and FTD patients, the improved prefractionated 2-DE procedure was applied to CSF from five AD patients, five FTD patients and five control subjects [32,81]. We found 37 proteins spots, which were up- or down regulated at least two times in AD patients compared to controls and 13 of these protein spots, representing seven different proteins were identified as isoforms of $\alpha-1 \beta$ glycoprotein, $\alpha$-2HS glycoprotein, TTR, $\alpha-1$ antitrypsin, $\beta-2-\mathrm{m}$, transferrin, and albumin.

In FTD patients, 26 protein spots were changed at least two times and 13 of these protein spots, representing seven different proteins, were identified as Zn- $\alpha$-2-glycoprotein (ZAG), proapoA1, $\beta$-2-m, TTR, RBP, serum albumin and alloalbumin. Our previous direct 2-DE study of the AD/FTD proteome showed that six/seven proteins respectively were significantly altered compared to controls. Some of the altered proteins were consistent between these two studies for example a reduced level of RBP in FTD. In contrast, CSF analysis of AD showed increased levels of one isoform of RBP, indicating a different role of RBP in the pathology of AD and FTD. Interestingly, several of the proteins found increased in the FTD study, including TTR, $\beta-2-\mathrm{m}$ and apoA1, has the potential to form amyloid fibrils [42]. To our knowledge, the TTR levels of FTD has not previously been studied, but in $\mathrm{AD}$ the CSF levels were shown to be decreased in an immunological study, not differentiating between TTR isoforms [66]. In contrast, the direct 2-DE study of the AD proteome [24] also showed an increased level of TTR, but that was the more acidic, low abundant isoform, compared to this study. This highlights again the importance and the capacity of 2-DE to quantitative different isoforms, because different isoforms may have different roles in the pathology of neurodegeneration.

However, direct and prefractionated 2-DE are two different proteomic approaches and a somewhat different analytical window is expected. Direct and prefractionated 2-D gels show different protein patterns, for example, the apoE and apoJ isoforms seems to be missing in the prefractionated 2-D gels, which may be explained by the fact that lipoproteins tend to adhere to plastics [50] and could be lost during LP-IEF or additional sample transfer steps in the prefractionation procedure.

Further studies of these protein changes have to be validated on a larger patient material and referable also with complementary methods in order to assess any of the proteins potential as biomarkers for AD/FTD. 


\subsection{SELDI analysis}

CSF proteins have also been analysed by the SELDI technique, instead of the 2-DE methodology in nine AD patients compared to ten healthy controls [16]. Using this approach, significant quantitative differences were detected including four over expressed and one under expressed polypeptides in $\mathrm{AD}$ patients compared to controls. The proteins were identified as cystatin $\mathrm{C}$, two isoforms of $\beta-2 \mathrm{~m}$, and one as VGF polypeptide, and one was unidentified. The combination of these five polypeptides was recommended as tools for the diagnosis of $\mathrm{AD}$ patients.

\subsection{Preparative 2-DE}

CSF proteins have been separated, purified and identified using the combination of LP-IEF, 1-D gels, gel elution, and MS/MS analysis ([23], Davidsson and Nilsson, unpublished results). We identified 55 proteins in human CSF and 23 of these proteins have never been identified in CSF for example brain expressed ring finger protein, coat gamma cop protein, beta-fodrin, undulin-1, dickkopf-3, brain secretory protein, $\mathrm{Zn}$ finger 4 protein and host cell factor. The possibility to identify new proteins in human CSF is important for the development of new neuronal markers for different types of neurodegenerative diseases.

The combination of 2-D LC/LC and MS/MS has been used for identification of proteins in ventricular CSF from ten subjects [102]. They found 249 proteins and $38 \%$ of them were unique to individuals, whereas only $6 \%$ of the identified proteins were found in all subjects. These results show a large subject-to-subject variability in the CSF samples.

\section{Conclusion}

Advances in biochemistry (including neurochemistry, proteomics, genomics) have increased our understanding of the central nervous system at the molecular level and applied us to screen for new biomarkers specific for neurodegenerative processes. In this study, we have summarized biomarker studies of CSF from patients with AD, FTD, or PD patients. CSF biomarkers for neurodegenerative diseases are of great value as diagnostic aids, especially early in the course of the disease, when the clinical symptoms are vague and diagnosis are difficult, but when therapeutic compounds have the greatest potential of being effective. Reliable
CSF biomarkers will be even more necessary when new therapeutic compounds reach the clinical phase. Much effort has focused on finding one single neurochemical biomarker for AD, one for FTD etc. First, this may be elusive unless the biomarker is related to a pathogenic step that is unique for $\mathrm{AD}$ or FTD etc. For example neurodegeneration or synaptic pathology is not only found in $\mathrm{AD}$, or in FTD. Biomarkers for neurodegenerative disorders should reflect all the pathogenic processes of that disease. Proteomic technology provide to analyse several biomarkers in a single CSF sample, which might discover new better instruments for clinical diagnosis of neurodegenerative diseases. By using a protein pattern, like in 2-D gels, or from SELDI analysis or from multi-parametric immunoassays, we are not limited by the sensitivity and specificity of any single biomarker.

Today, discrimination of AD from controls and from other neurological diseases has been improved by simultaneous analysis of both $\mathrm{A} \beta(1-42)$, total-tau, and phosphorylated tau, where a combination of low levels of CSF-A $\beta 1-42$ and high levels of CSF-tau and CSF-phospho-tau is associated with an AD diagnosis. Detection of new biomarkers will further strengthen diagnosis and provide useful information in drug trials. The combination of immunoassays and proteomic methods show that AD, FTD, and PD patients express differential proteins patterns, which reflect divergent underlying pathophysiological mechanisms and neuropathological changes in these diseases. However, all these new potential markers confirm the need to implement new approaches for biomarker analysis i.e. new complementary multiparametric assays for simultaneous quantification of a set of peptides/proteins for diagnostic purposes and also for studying treatment effects in neurodegenerative diseases.

\section{References}

[1] B. Akerstrom and L. Bjorck, A physicochemical study of protein $\mathrm{G}$, a molecule with unique immunoglobulin G-binding properties, J Biol Chem 261 (1986), 10240-10247.

[2] N. Andreasen, L. Minthon, A. Clarberg, P. Davidsson, J. Gottfries, E. Vanmechelen, H. Vanderstichele, B. Winblad and K. Blennow, Sensitivity, specificity, and stability of CSFtau in AD in a community-based patient sample, Neurology 53 (1999), 1488-1494.

[3] H. Arai, T. Satoh-Nakagawa, M. Higuchi, Y. Morikawa, M. Miura, H. Kawakami, H. Seki, S. Takase and H. Sasaki, No increase in cerebrospinal fluid tau protein levels in patients with vascular dementia, Neurosci Lett 256 (1998), 174-176. 
[4] P. Bertrand, J. Poirier, T. Oda, C.E. Finch and G.M. Pasinetti, Association of apolipoprotein E genotype with brain levels of apolipoprotein E and apolipoprotein $\mathbf{J}$ (clusterin) in Alzheimer disease, Brain Res Mol Brain Res 33 (1995), 174178 .

[5] M. Bier, US Patent 4588 492, 5-13-1986, 5-7-1984.

[6] L. Bjorck and G. Kronvall, Purification and some properties of streptococcal protein $\mathrm{G}$, a novel IgG-binding reagent, $J$ Immunol 133 (1984), 969-974.

[7] K. Björhall, T. Miliotis and P. Davidsson, Comparison of different depletion strategies for improved resolution in proteomic analysis of human serum samples, Proteomics (2004), in press.

[8] K. Blennow, P. Davidsson, A. Wallin, P. Fredman, C.G. Gottfries, J.E. Mansson and L. Svennerholm, Differences in cerebrospinal fluid gangliosides between "probable Alzheimer's disease" and normal aging, Aging 4 (1992), 301-306.

[9] K. Blennow, C. Hesse and P. Fredman, Cerebrospinal fluid apolipoprotein E is reduced in Alzheimer's disease, Neuroreport 20 (1994), 2534-2536.

[10] K. Blennow, A. Wallin, H. Agren, C. Spenger, J. Siegfried and E. Vanmechelen, Tau protein in cerebrospinal fluid: a biochemical marker for axonal degeneration in Alzheimer disease? Mol Chem Neuropathol 26 (1995), 231-245.

[11] K. Blennow, P. Davidsson, A. Wallin and R. Ekman, Chromogranin A in cerebrospinal fluid: a biochemical marker for synaptic degeneration in Alzheimer's disease? Dementia 6 (1995), 306-311.

[12] K. Blennow, N. Bogdanovic, I. Alafuzoff, R. Ekman and P. Davidsson, Synaptic pathology in Alzheimer's disease: relation to severity of dementia, but not to senile plaques, neurofibrillary tangles, or the ApoE4 allele, J Neural Transm 103 (1996), 603-618.

[13] N. Bogdanovic, P. Davidsson, I. Volkmann, B. Winblad and K. Blennow, Growth-associated protein GAP-43 in the frontal cortex and in the hippocampus in Alzheimer's disease: an immunohistochemical and quantitative study, J Neural Transm 107 (2000), 463-478.

[14] M.D.P. Boyle, E.J. Siden and K.J. Reis, Selective colony blotting to expand bacterial surface receptors: applications to receptors for rat immunoglobulins, Biotechniques 6 (1988), 130-136.

[15] L.E. Bradbury, J.F. LeBlanc and D.B. McCarthy, ProteinChip array-based amyloid beta assays, Methods Mol Biol 264 (2004), 245-257.

[16] O. Carrette, I. Demalte, A. Scherl, O. Yalkinoglu, G. Corthals, P. Burkhard, D.F. Hochstrasser and J.C. Sanchez, A panel of cerebrospinal fluid potential biomarkers for the diagnosis of Alzheimer's disease, Proteomics 3 (2003), 14861494.

[17] L.H. Choe, L.H. Dutt, N. Relkin and K.H. Lee, Studies of potential cerebrospinal fluid molecular markers for Alzheimer's disease, Electrophoresis 23 (2002), 2247-2251.

[18] E.H. Corder, A.M. Saunders, W.J. Strittmatter, D.E. Schmechel, P.C. Gaskell, G.W. Small, A.D. Roses, J.L. Haines and M.A. Pericak-Vance, Gene dose of apolipoprotein E type 4 allele and the risk of Alzheimer's disease in late onset families, Science 13 (1993), 921-923.

[19] P. Davidsson, R. Jahn, J. Bergquist, R. Ekman and K. Blennow, Synaptotagmin, a synaptic vesicle protein, is present in human cerebrospinal fluid: a new biochemical marker for synaptic pathology in Alzheimer disease? Mol Chem Neuropathol 2 (1996), 195-210.
[20] P. Davidsson and K. Blennow, Neurochemical dissection of synaptic pathology in Alzheimer's disease, Int Psychogeriatr 1 (1998), 11-23.

[21] P. Davidsson, M. Puchades and K. Blennow, Identification of synaptic vesicle, pre- and postsynaptic proteins in human cerebrospinal fluid using liquid-phase isoelectric focusing, Electrophoresis 20 (1999), 431-437.

[22] P. Davidsson, A. Westman, M. Puchades, C.L. Nilsson and K. Blennow, Characterization of proteins from human cerebrospinal fluid by a combination of preparative twodimensional liquid-phase electrophoresis and matrix-assisted laser desorption/ionization time-of-flight mass spectrometry, Anal Chem 1 (1999), 642-647.

[23] P. Davidsson, L. Paulson, C. Hesse, K. Blennow and C.L. Nilsson, Proteome studies of human cerebrospinal fluid and brain tissue using a preparative two-dimensional electrophoresis approach prior to mass spectrometry, Proteomics 3 (2001), 444-452.

[24] P. Davidsson, S. Folkesson, M. Christiansson, M. Lindbjer, B. Dellheden, K. Blennow and A. Westman-Brinkmalm, Identification of proteins in human cerebrospinal fluid using liquid-phase isoelectric focusing as a prefractionation step followed by two-dimensional gel electrophoresis and matrixassisted laser desorption/ionisation mass spectrometry, Rapid Commun Mass Spectrom 16 (2002), 2083-2088.

[25] P. Davidsson, A. Westman-Brinkmalm, C.L. Nilsson, M. Lindbjer, L. Paulson, N. Andreasen, M. Sjogren and K. Blennow, Proteome analysis of cerebrospinal fluid proteins in Alzheimer patients, Neuroreport 13 (2002), 611-615.

[26] P. Davidsson, M. Sjogren, N. Andreasen, M. Lindbjer and C.L. Nilsson, A. Westman-Brinkmalm and K. Blennow, Studies of the pathophysiological mechanisms in frontotemporal dementia by proteome analysis of CSF proteins, Brain Res Mol Brain Res 109 (2002), 128-133.

[27] C.A. Davies, D.M. Mann, P.Q. Sumpter and P.O. Yates, A quantitative morphometric analysis of the neuronal and synaptic content of the frontal and temporal cortex in patients with Alzheimer's disease, J Neurol Sci 78 (1987), 151-164.

[28] S.T. DeKosky and S.W. Scheff, Synapse loss in frontal cortex biopsies in Alzheimer's disease: correlation with cognitive severity, Ann Neurol 5 (1990), 457-464.

[29] J.M. Dietschy and S.D. Turley, Cholesterol metabolism in the brain, Curr Opin Lipidol 12 (2001), 105-112.

[30] N.A. Elshourbagy, W.S. Liao, R.W. Mahley and J.M. Taylor, Apolipoprotein E mRNA is abundant in the brain and adrenals, as well as in the liver, and is present in other peripheral tissues of rats and marmosets, Proc Natl Acad Sci USA 82 (1985), 203-207.

[31] L.A. Farrer, L.A. Cupples J.L. Haines, B. Hyman, W.A. Kukull, R. Mayeux, R.H. Myers, M.A. Pericak-Vance, N. Risch and C.M. van Duijn, Effects of age, sex, and ethnicity on the association between apolipoprotein E genotype and Alzheimer disease. A meta-analysis. APOE and Alzheimer Disease Meta Analysis Consortium, JAMA 278 (1997), 1349-1356.

[32] S. Folkesson Hansson, M. Puchades, K. Blennow, M. Sjogren and P. Davidsson, Validation of a prefractionation method followed by two-dimensional electrophoresis - Applied to cerebrospinal fluid proteins from frontotemporal dementia patients, Proteome Sci 2 (2004), 7-21.

[33] A. Fonteh and M. Harrington, Importance of proteins that metabolize polyunsaturated fatty acids in the pathogenesis of Alzheimer's disease, In 5th Siena meeting, from genome to proteome: functional proteomics, 2002, Italy. 
[34] D. Galasko, L. Chang, R. Motter, C.M. Clark, J. Kaye, D. Knopman, R. Thomas, D. Kholodenko, D. Schenk, I. Lieberburg, B. Miller, R. Green, R. Basherad, L. Kertiles, M.A. Boss and P. Seubert, High cerebrospinal fluid tau and low amyloid beta42 levels in the clinical diagnosis of Alzheimer disease and relation to apolipoprotein E genotype, $\mathrm{Arch} \mathrm{Neu}$ rol 55 (1998), 937-945.

[35] E. Gianazza and P. Arnaud, A general method for fractionation of plasma proteins. Dye-ligand affinity chromatography on immobilized Cibacron blue F3-GA, J Biochem 203 (1982), 637-641.

[36] J. Gottfries, M. Sjögren, B. Holmberg, L. Rosengren, P. Davidsson and K. Blennow, Proteomics for drug target discovery, Chemomatrics and Intelligent Laboratory Systems (2004), in press.

[37] N.I. Govorukhina, A. Keizer-Gunnink, A.G.J. van der Zee, S. de Jong, H.W.A. de Bruijn and R. Bischoff, J Chrom A 1009 (2003), 171-178.

[38] S. Greber, G. Lubec, N. Cairns and M. Fountoulakis, Decreased levels of synaptosomal associated protein 25 in the brain of patients with Down syndrome and Alzheimer's disease, Electrophoresis 20 (1999), 928-934.

[39] A.J. Green, R.J. Harvey, E.J. Thompson and M.N. Rossor, Increased tau in the cerebrospinal fluid of patients with frontotemporal dementia and Alzheimer's disease, Neurosci Lett 259 (1999), 133-135.

[40] J.E. Hamos, L.J. DeGennaro and D.A. Drachman, Synaptic loss in Alzheimer's disease and other dementias, Neurology 39 (1989), 355-361.

[41] S. Hanash, F. Brichory and D. Beer, A proteomic approach to the identification of lung cancer markers, Dis Markers 17 (2001), 295-300.

[42] K. Hakansson, M.R. Emmett, A.G. Marshall, P. Davidsson and C.L. Nilsson, Structural analysis of 2D-gel-separated glycoproteins from human cerebrospinal fluid by tandem high-resolution mass spectrometry, J Proteome Res 2 (2003), $581-588$.

[43] S.D. Harr, L. Uint, R. Hollister, B.T. Hyman and A.J. Mendez, Brain expression of apolipoproteins E, J, and A-I in Alzheimer's disease, J Neurochem 66 (1996), 2429-2435.

[44] M.G. Harrington and C.R. Merril, Two-dimensional electrophoresis and "ultrasensitive" silver staining of cerebrospinal fluid proteins in neurological diseases, Clin Chem 30 (1984), 1933-1937.

[45] M.G. Harrington, C.R. Merril and E.F. Torrey, Differences in cerebrospinal fluid proteins between patients with schizophrenia and normal persons, Clin Chem 31 (1985), $722-726$.

[46] M.G. Harrington and Y.P.G. Kennedy, The clinical use of cerebrospinal fluid studies in demyelinating neurological diseases, Postgrad Med J 63 (1987), 735-740.

[47] M.G. Harrington and C.R. Merril, Cerebrospinal fluid protein analysis in diseases of the nervous system, J Chromatogr $\mathbf{4 2 9}$ (1988), 345-358.

[48] C. Hesse, N. Bogdanovic, P. Davidsson and K. Blennow, A quantitative and immunohistochemical study on apolipoprotein E in brain tissue in Alzheimer's disease, Dement Geriatr Cogn Disord 6 (1999), 452-459.

[49] C. Hesse, L. Rosengren, E. Vanmechelen, H. Vanderstichele, C. Jensen, P. Davidsson and K. Blennow, Cerebrospinal fluid markers for Alzheimer's disease evaluated after acute ischemic stroke, J Alzheimers Dis 2 (2000), 199-206.

[50] C. Hesse, H. Larsson, P. Fredman, L. Minthon, N. Andreasen, P. Davidsson and K. Blennow, Measurement of apolipopro- tein E (apoE) in cerebrospinal fluid, Neurochem Res $\mathbf{2 5}$ (2000), 511-517.

[51] C. Hesse, L. Rosengren, N. Andreasen, P. Davidsson, H. Vanderstichele, E. Vanmechelen and K. Blennow, Transient increase in total tau but not phospho-tau in human cerebrospinal fluid after acute stroke, Neurosci Lett 297 (2001), 187-190.

[52] C. Hesse, C.L. Nilsson, K. Blennow and P. Davidsson, Identification of the apolipoprotein E4 isoform in cerebrospinal fluid with preparative two-dimensional electrophoresis and matrix assisted laser desorption/ionization-time of flightmass spectrometry, Electrophoresis 22 (2001), 1834-1837.

[53] C. Hock, S. Golombowski, F. Muller-Spahn, W. Naser, K. Beyreuther, U. Monning, D. Schenk, C. Vigo-Pelfrey, A.M. Bush, R. Moir, R.E. Tanzi, J.H. Growdon and R.M. Nitsch, Cerebrospinal fluid levels of amyloid precursor protein and amyloid beta-peptide in Alzheimer's disease and major depression - inverse correlation with dementia severity, Eur Neurol 39 (1998), 111-118.

[54] F. Hulstaert, K. Blennow, A. Ivanoiu, H.C. Schoonderwaldt, M. Riemenschneider M, P.P. De Deyn, C. Bancher, P. Cras, J. Wiltfang, P.D. Mehta, K. Iqbal, H. Pottel, E. Vanmechelen and $\mathrm{H}$. Vanderstichele, Improved discrimination of AD patients using beta-amyloid(1-42) and tau levels in CSF, Neurology 52 (1999), 1555-1562.

[55] N. Ida, T. Hartmann, J. Pantel, J. Schroder, R. Zerfass, H. Forstl, R. Sandbrink, C.L. Masters and K. Beyreuther, Analysis of heterogeneous A4 peptides in human cerebrospinal fluid and blood by a newly developed sensitive Western blot assay, J Biol Chem 271 (1996), 22908-22914.

[56] H. Idborg-Bjorkman, P.O. Edlund, O.M. Kvalheim, I. Schuppe-Koistinen and S.P. Jacobsson, Screening of biomarkers in rat urine using LC/electrospray ionization-MS and two-way data analysis, Anal Chem 75 (2003), 47844792.

[57] M. Jensen, J. Schroder, M. Blomberg, B. Engvall, J. Pantel, N. Ida, H. Basun, L.O. Wahlund, E. Werle, M. Jauss, K. Beyreuther, L. Lannfelt and T. Hartmann, Cerebrospinal fluid A beta42 is increased early in sporadic Alzheimer's disease and declines with disease progression, Ann Neurol 45 (1999), 504-511.

[58] M.B. Jones, H.J. Krutzsch, H.J. Shu, Y.M. Zhao, L.A. Liotta, E.C. Kohn and E.F. Petricoin, Proteomic analysis and identification of new biomarkers and therapeutic targets for invasive ovarian cancer, Proteomics 2 (2002), 76-84.

[59] D. Lefranc, P. Vermersch, J. Dallongeville, C. DaemsMonpeurt, H. Petit and A. Delacourte, Relevance of the quantification of apolipoprotein $\mathrm{E}$ in the cerebrospinal fluid in Alzheimer's disease, Neurosci Lett 212 (1996), 91-94.

[60] M. Landen, C. Hesse, P. Fredman, B. Regland, A. Wallin and $\mathrm{K}$. Blennow, Apolipoprotein $\mathrm{E}$ in cerebrospinal fluid from patients with Alzheimer's disease and other forms of dementia is reduced but without any correlation to the apoE4 isoform, Dementia 7 (1996), 273-278.

[61] P. Lewczuk, H. Esselmann, T.W. Groemer, M. Bibl, J.M. Maler, P. Steinacker, M. Otto, J. Kornhuber and J. Wiltfang, Amyloid beta peptides in cerebrospinal fluid as profiled with surface enhanced laser desorption/ionization time-offlight mass spectrometry: evidence of novel biomarkers in Alzheimer's disease, Biol Psychiatry 55 (2004), 524-530.

[62] A.M. Lidstrom, C. Hesse, L. Rosengren, P. Fredman, P. Davidsson and K. Blennow, Normal levels of clusterin in cerebrospinal fluid in Alzheimer's disease, and no change 
after acute ischemic stroke, J Alzheimers Dis 3 (2001), 435442.

[63] R.W. Mahley, Apolipoprotein E: cholesterol transport protein with expanding role in cell biology, Science 240 (1988), 622 630.

[64] C.L. Masters, G. Simms, N.A. Weinman, G. Multhaup, B.L. McDonald and K. Beyreuther, Amyloid plaque core protein in Alzheimer disease and Down syndrome, Proc Natl Acad Sci USA 82 (1985), 4245-4249.

[65] W.H. McDonald and J.R. Yates, Shotgun proteomics and biomarker discovery, Dis. Markers 18 (2002), 99-105.

[66] A. Merched, J.M. Serot, S. Visvikis, D. Aguillon, G. Faure and G. Sies, Apolipoprotein E, transthyretin and actin in the CSF of Alzheimer's patients: relation with the senile plaques and cytoskeleton biochemistry, FEBS Lett 425 (1998), 225228.

[67] A. Merched, Y. Xia, S. Visvikis, J.M. Serot and G. Siest, Decreased high-density lipoprotein cholesterol and serum apolipoprotein AI concentrations are highly correlated with the severity of Alzheimer's disease, Neurobiol Aging 1 (2000), 7-30.

[68] C.R. Merril and M.G. Harrington, "Ultrasensitive" silver stains: their use exemplified in the study of normal human cerebrospinal fluid proteins separated by two-dimensional electrophoresis, Clin Chem 30 (1984), 1938-1942.

[69] L. Molina, J. Touchon, M. Herpe, D. Lefranc, L. Duplan, J.P. Cristol, R. Sabatier, P. Vermersch, B. Pau and C. MourtonGilles, Tau and apo E in CSF: potential aid for discriminating Alzheimer's disease from other dementias, Neuroreport 10 (1999), 3491-3495

[70] C.L. Nilsson, M. Puchades, A. Westman, K. Blennow and P. Davidsson, Identification of proteins in a human pleural exudate using two-dimensional preparative liquid-phase electrophoresis and matrix-assisted laser desorption/ionization mass spectrometry, Electrophoresis 20 (1999), 860-865.

[71] A. Olsson, K. Hoglund, M. Sjogren, N. Andreasen, L. Minthon, L. Lannfelt, K. Buerger, H.J. Moller, H. Hampel, P. Davidsson and K. Blennow, Measurement of alpha- and betasecretase cleaved amyloid precursor protein in cerebrospinal fluid from Alzheimer patients, Exp Neurol 183 (2003), 74 80

[72] M.R. Palmert, M. Usiak, R. Mayeux, M. Raskind, W.W. Tourtellotte and S.G. Younkin, Soluble derivatives of the beta amyloid protein precursor in cerebrospinal fluid: alterations in normal aging and in Alzheimer's disease, Neurology $\mathbf{4 0}$ (1990), 1028-1034.

[73] J.M. Pasternack, M.R. Palmert, M. Usiak, R. Wang, H. Zurcher-Neely, P.A. Gonzalez-De Whitt, M.B. Fairbanks, T. Cheung, D. Blades and R.L. Heinrikson, Alzheimer's disease and control brain contain soluble derivatives of the amyloid protein precursor that end within the beta amyloid protein regio, Biochemistry 10 (1992), 10936-10940.

[74] C.P. Paweletz, B. Trock, M. Pennanen, T. Tsangaris, C. Magnant L.A. Liotta and E.F. Petricoin, Proteomic patterns of nipple aspirate fluids obtained by SELDI-TOF: potential for new biomarkers to aid in the diagnosis of breast cancer, Dis Markers 17 (2001), 301-307.

[75] E.F. Petricoin, A.M. Ardekani, B.A. Hitt, P.J. Levine, V.A. Fusaro, S.M. Steinberg, G.B. Mills, C. Simone, D.A. Fishman, E.C. Kohn and L.A. Liotta, Use of proteomic patterns in serum to identify ovarian cancer, Lancet 359 (2002), 572 577.

[76] R. Pieper, C.L. Gatlin, A.J. Makusky, P.S. Russo, C.R. Schatz, S.S. Miller, Q. Su, A.M. McGrath, M.A. Estock,
P.P. Parmar, M. Zhao, S.T. Huang, J. Zhou, F. Wang, R. Esquer-Blasco, N.L. Anderson, J. Taylor and S. Steiner, The human serum proteome: display of nearly 3700 chromatographically separated protein spots on two-dimensional electrophoresis gels and identification of 325 distinct proteins, Proteomics 3 (2003), 1345-1364.

[77] T. Pirttila, K.S. Kim, P.D. Mehta, H. Frey and H.M. Wisniewski, Soluble amyloid beta-protein in the cerebrospinal fluid from patients with Alzheimer's disease, vascular dementia and controls, J Neurol Sci 127 (1994), 90-95.

[78] T. Pirttila, P.D. Mehta, H. Soininen, K.S. Kim, O. Heinonen, L. Paljarvi, O. Kosunen, P.S.R. Riekkinen and H.M. Wisniewski, Cerebrospinal fluid concentrations of soluble amyloid beta-protein and apolipoprotein $\mathrm{E}$ in patients with Alzheimer's disease: correlations with amyloid load in the brain, Arch Neurol 53 (1996), 189-193.

[79] R.E. Pitas, J.K. Boyles, S.H. Lee, D. Foss and R.W. Mahley, Astrocytes synthesize apolipoprotein E and metabolize apolipoprotein E-containing lipoproteins, Biochim Biophys Acta 917 (1987), 148-161.

[80] R. Prior, U. Monning, U. Schreiter-Gasser, A. Weidemann, K. Blennow, C.G. Gottfries, C.L. Masters and K. Beyreuther, Quantitative changes in the amyloid beta A4 precursor protein in Alzheimer cerebrospinal fluid, Neurosci Lett 124 (1991), 69-73.

[81] M. Puchades, S.F. Hansson, C.L. Nilsson, N. Andreasen, K. Blennow and P. Davidsson, Proteomic studies of potential cerebrospinal fluid protein markers for Alzheimer's disease, Brain Res Mol Brain Res 118 (2003), 140-146.

[82] M. Puchades, Development of proteomic methods for studying cerebrospinal fuid proteins in Alzheimer's disease, 2003, thesis, University of Göteborg.

[83] G.W. Rebeck, S.D. Harr, D.K. Strickland and B.T. Hyman, Multiple, diverse senile plaque-associated proteins are ligands of an apolipoprotein $\mathrm{E}$ receptor, the alpha 2-macroglobulin receptor/low-density-lipoprotein receptorrelated protein, Ann Neurol 37 (1995), 211-217.

[84] A.D. Roses, Apolipoprotein E alleles as risk factors in Alzheimer's disease, Annu Rev Med 47 (1996), 387-400.

[85] A.M. Saunders, W.J. Strittmatter, D. Schmechel, P.H. George-Hyslop, M.A. Pericak-Vance, S.H. Joo, B.L. Rosi, J.F. Gusella, D.R. Crapper-MacLachlan, M.J. Alberts et al., Association of apolipoprotein E allele epsilon 4 with lateonset familial and sporadic Alzheimer's disease, Neurology 43 (1993), 1467-1472.

[86] G. Schlaf, C. Salje, A. Wetter, K. Stuertz, K. Felgenhauer and M. Mader, Determination of synapsin I and synaptophysin in body fluids by two-site enzyme-linked immunosorbent assays, J Immunol Methods 213 (1998), 191-199.

[87] P. Seubert, C. Vigo-Pelfrey, F. Esch, M. Lee, H. Dovey, D. Davis, S. Sinha, M. Schlossmacher, J. Whaley, C. Swindlehurst et al., Isolation and quantification of soluble Alzheimer's beta-peptide from biological fluids, Nature $\mathbf{3 5 9}$ (1992), 325-327.

[88] P. Seubert, T. Oltersdorf, M.G. Lee, R. Barbour, C. Blomquist, D.L. Davis, K. Bryant, L.C. Fritz, D. Galasko and L.J. Thal, Secretion of beta-amyloid precursor protein cleaved at the amino terminus of the beta-amyloid peptide, Nature 361 (1993), 260-263.

[89] A. Sickmann, W. Dormeyer, S. Wortelkamp, D. Woitallad, W. Kuhn and H.E. Meyer, Identification of proteins from human cerebrospinal fluid, separated by two-dimensional polyacrylamide gel electrophoresis, Electrophoresis 21 (2000), $2721-2728$ 
[90] M. Sjogren, L. Minthon, P. Davidsson, A.K. Granerus, A. Clarberg, H. Vanderstichele, E. Vanmechelen, A. Wallin and K. Blennow, CSF levels of tau, beta-amyloid(1-42) and GAP43 in frontotemporal dementia, other types of dementia and normal aging, J Neural Transm 107 (2000), 563-579.

[91] M. Sjogren, P. Davidsson, M. Tullberg, L. Minthon, A. Wallin, C. Wikkelso, A.K. Granerus, H. Vanderstichele, E. Vanmechelen and K. Blennow, Both total and phosphorylated tau are increased in Alzheimer's disease, $J$ Neurol Neurosurg Psychiatry 70 (2001), 624-630.

[92] M. Sjogren, P. Davidsson, J. Gottfries, H. Vanderstichele, A. Edman, E. Vanmechelen, A. Wallin and K. Blennow, The cerebrospinal fluid levels of tau, growth-associated protein-43 and soluble amyloid precursor protein correlate in Alzheimer's disease, reflecting a common pathophysiological process, Dement Geriatr Cogn Disord 12 (2001), $257-$ 264.

[93] L.F. Steel, M.G. Trotter, P.B. Nakajima, T.S. Mattu, G. Gonye and T. Block, Efficient and specific removal of albumin from human serum samples, Molecular and Cellular Proteomics 2 (2003), 262-270.

[94] W.J. Strittmatter, A.M. Saunders, D. Schmechel, M. Pericak-Vance, J. Enghild, G.S. Salvesen and A.D. Roses, Apolipoprotein E: high-avidity binding to beta-amyloid and increased frequency of type 4 allele in late-onset familial Alzheimer disease, Proc Natl Acad Sci USA 90 (1993), 1977 1981.

[95] C.I. Sze, H. Bi, B.K. Kleinschmidt-DeMasters, C.M. Filley and L.J. Martin, Selective regional loss of exocytotic presynaptic vesicle proteins in Alzheimer's disease brains, $\mathrm{J} \mathrm{Neu}$ rol Sci 175 (2000), 81-90.

[96] M. Takashima, Y. Kuramitsu, Y. Yokoyama, N. Iizuka, T. Toda, I. Sakaida, K. Okita, M. Oka and K. Nakamura, Proteomic profiling of heat shock protein 70 family members as biomarkers for hepatitis $\mathrm{C}$ virus-related hepatocellular carcinoma, Proteomics 3 (2003), 2487-2493.

[97] R.D. Terry, E. Masliah, D.P. Salmon, N. Butters, R. DeTeresa, R. Hill, L.A. Hansen and R. Katzman, Physical basis of cognitive alterations in Alzheimer's disease: synapse loss is the major correlate of cognitive impairment, Ann Neurol 4 (1991), 572-580.
[98] T. Uchihara, C. Duyckaerts, Y. He, K. Kobayashi, D. Seilhean, P. Amouyel and J.J. Hauw, ApoE immunoreactivity and microglial cells in Alzheimer's disease brain, Neurosci Lett 195 (1995), 5-8.

[99] M. Vandermeeren, M. Mercken, E. Vanmechelen, J. Six, A. van de Voorde, J.J. Martin and P. Cras, Detection of tau proteins in normal and Alzheimer's disease cerebrospinal fluid with a sensitive sandwich enzyme-linked immunosorbent assay, J Neurochem 61 (1993), 1828-1834.

[100] Y.Y. Wang, P. Cheng and D.W. Chan, A simple affinity spin tube filter method for removing high-abundant common proteins or enriching low-abundant biomarkers for serum proteomic analysis, Proteomics 3 (2003), 243-248.

[101] W.E. Van Nostrand, S.L. Wagner, W.R. Shankle, J.S. Farrow, M. Dick, J.M. Rozemuller, M.A. Kuiper, E.C. Wolters, J. Zimmerman and C.W. Cotman, Decreased levels of soluble amyloid beta-protein precursor in cerebrospinal fluid of live Alzheimer disease patients, Proc Natl Acad Sci USA 89 (1992), 2551-2555.

[102] B.R. Wenner, M.A. Lovell and B.C. Lynn, Proteomic analysis of human ventricular cerebrospinal fluid from neurologically normal, elderly subjects using two-dimensional LC-MS/MS, J Proteome Res 3 (2004), 97-103.

[103] C. Vigo-Pelfrey, D. Lee, P. Keim, I. Lieberburg and D.B. Schenk, Characterization of beta-amyloid peptide from human cerebrospinal fluid, J Neurochem 61 (1993), 1965-1968.

[104] C. Vigo-Pelfrey, P. Seubert, R. Barbour, C. Blomquist, M. Lee, D. Lee, F. Coria, L. Chang, B. Miller, I. Lieberburg et al., Elevation of microtubule-associated protein tau in the cerebrospinal fluid of patients with Alzheimer's disease, Neurology 45 (1995), 788-793.

[105] J. Wiltfang, H. Esselmann, M. Bibl, A. Smirnov, M. Otto, S. Paul, B. Schmidt, H.W.Klafki, M. Maler, T. Dyrks, M. Bienert, M. Beyermann, E. Ruther and J. Kornhuber, Highly conserved and disease-specific patterns of carboxyterminally truncated Abeta peptides 1-37/38/39 in addition to 1-40/42 in Alzheimer's disease and in patients with chronic neuroinflammation, J Neurochem 81 (2002), 481-496.

[106] X. Yuan, T. Russell, G. Wood and M. Desiderio, Analysis of the human lumbar cerebrospinal fluid proteome, Electrophoresis 23 (2002), 1185-1196. 


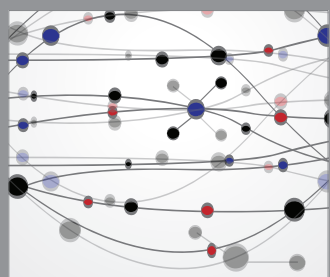

The Scientific World Journal
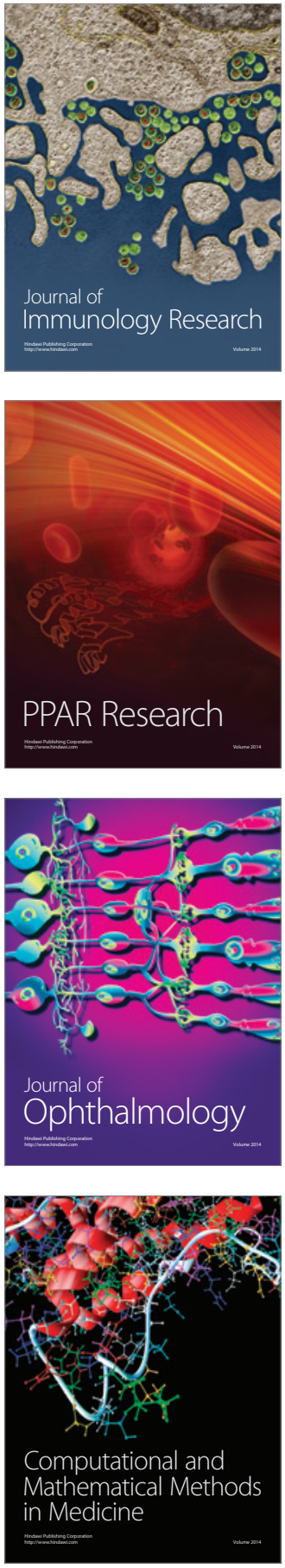

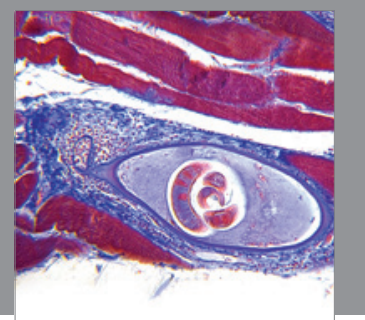

Gastroenterology

Research and Practice
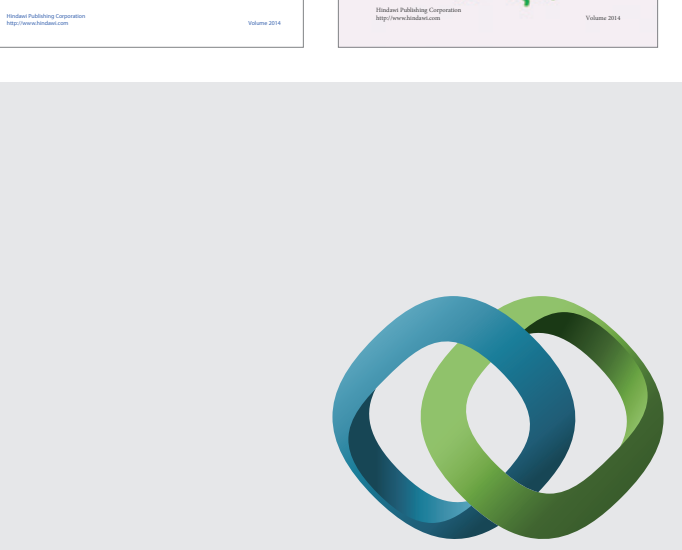

\section{Hindawi}

Submit your manuscripts at

http://www.hindawi.com
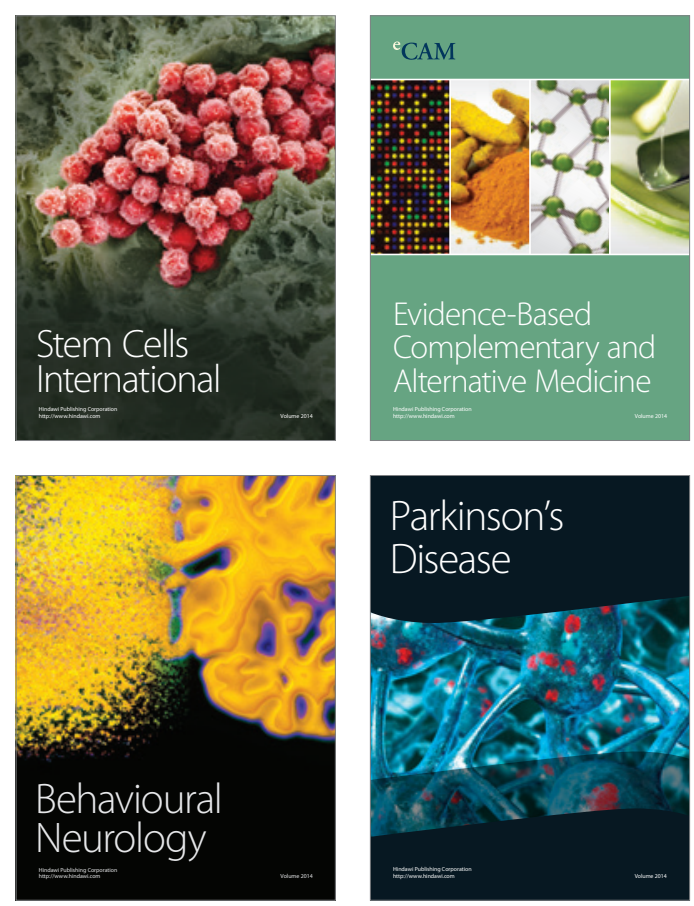

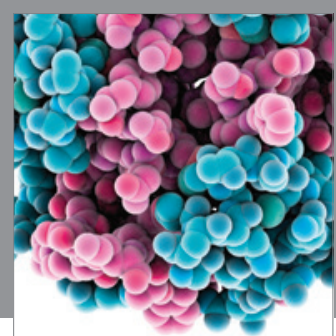

Journal of
Diabetes Research

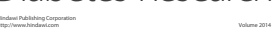

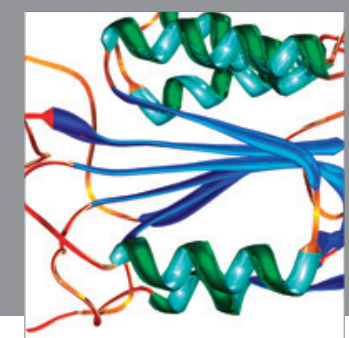

Disease Markers
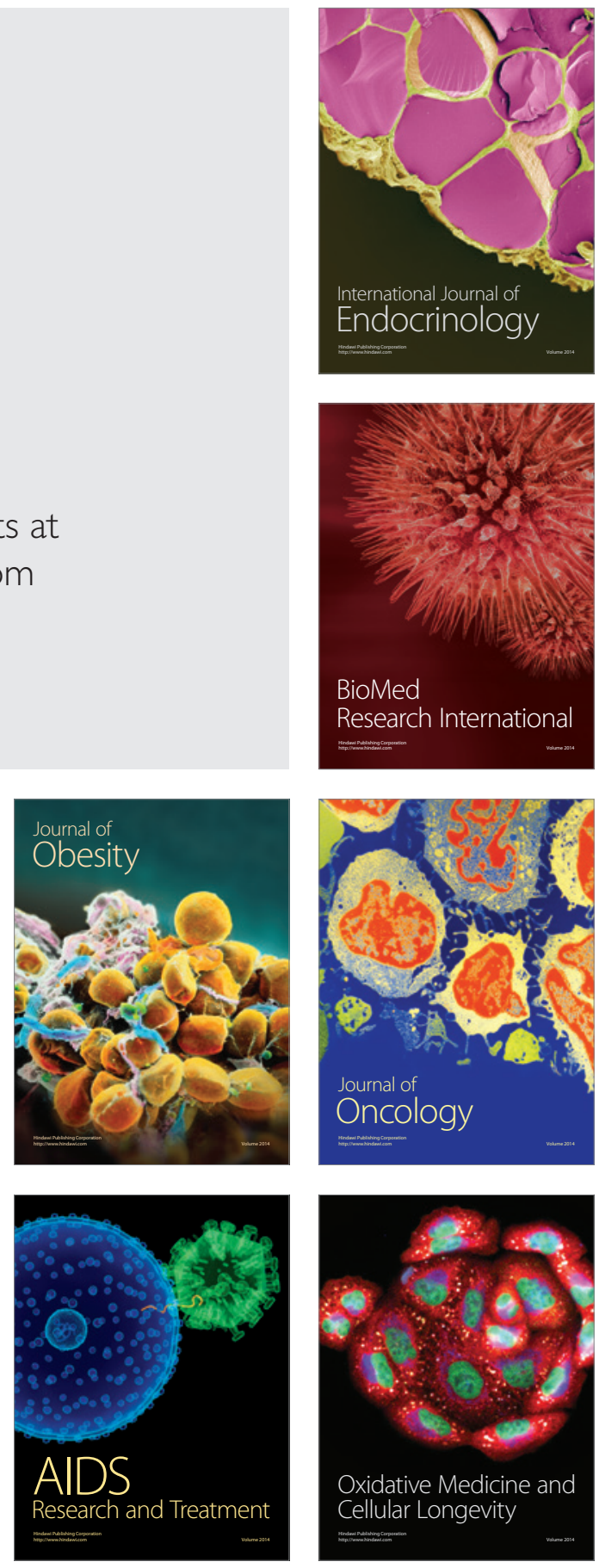